\title{
Perceptions of Parenting, Parent-Child Activities and Children's Extracurricular Activities in Times of COVID-19
}

\author{
Beatriz Ilari $\mathbb{1}^{1} \cdot$ Eun $\mathrm{Cho}^{2} \cdot$ Jialin $\mathrm{Li}^{1} \cdot$ Alfredo Bautista $^{3}$ \\ Accepted: 4 November 2021 / Published online: 24 November 2021 \\ (c) The Author(s), under exclusive licence to Springer Science+Business Media, LLC, part of Springer Nature 2021
}

\begin{abstract}
The purpose of this study was to explore perceptions of parenting and parent-child activities in American families with children aged 0-16 after social distance measures were put in place. Through an online questionnaire, we examined the extent to which parental role, age, education, and perceptions of work productivity impacted parent perceptions of six parenting categories (positive parenting, inconsistent discipline, positive relationships, positive emotions, self-efficacy, and routine management) during the initial months of the pandemic. We also examined children's participation in extracurricular activities, before and after measures of social distancing were implemented. Perceptions of parenting did not differ based on parental roles, education and age, but work productivity had an impact on parents' perceptions of their own feelings and emotions. Parents who described themselves as highly productive reported higher scores for positive emotions, suggesting a link between work and parental wellbeing. A discrepancy was found between the activities that parents liked and disliked doing with their children, with homework and academic activities being the least liked of all. Children's participation in extracurricular activities was also significantly reduced after social distancing was mandated, with arts activities (music in particular) suffering the least amount of reduction. Findings are discussed considering earlier studies on parenting during COVID-19 and concerted cultivation. Implications for future parenting research are outlined.
\end{abstract}

Keywords Parenting $\cdot$ COVID-19 $\cdot$ Parental cognitions $\cdot$ School-aged children $\cdot$ Extracurricular activities (EA)

\section{Highlights}

- Online questionnaire with American parents during the initial months of the pandemic.

- Parents who perceived themselves as more productive at work showed higher ratings for positive emotions.

- Homework and academic activities were rated as the least-liked activities that parents did with their children after social distancing was mandated.

- There was a significant reduction of extracurricular activities following "safer at home" measures, with the arts (music) suffering the least amount of reduction.

Supplementary information The online version contains supplementary material available at https://doi.org/10.1007/s10826021-02171-3.

Beatriz Ilari

ilari@usc.edu

1 University of Southern California, Thornton School of Music, 840 W. 34th Street, Los Angeles, CA 90089, USA

2 University of California Riverside, Experimental Acoustics Research Studio (EARS), 1935 Chicago Avenue, Unit B, Riverside, CA 92507, USA

3 Education University of Hong Kong - Department of Early Childhood Education, 10 Lo Ping Rd, Ting Kok, Hong Kong, SAR, China
In 2020, the world was turned on its head due to the outbreak of COVID-19. On March 11, the World Health Organization declared COVID-19 a pandemic. Several cities across the world adopted "safer-at-home" (or social distancing) measures, which resulted in the closure of daycares, schools, offices and businesses, and consequently in the transfer of daily activities of work, education and leisure into the home. Job losses, insecurity towards the future, fears of becoming ill, social distancing and the inability to be with loved ones took an emotional toll on children and adults. Parents of young and school-aged children were hit particularly hard by the loss of support systems that resulted in the disruption of family routines, 
and by the impact of social and physical distancing on developing children and youth.

Parenting has long been recognized as a high-pressure activity given the many demands of childcare, the loss of family and community support as a result of modern lifestyles, and the anxieties associated with pressure to conform to social norms in a competitive world (Furedi, 2001; Lareau, 2011). The pandemic disrupted the lives of parents-and families, by extension-in unimagined ways. Many parents worldwide have lost their jobs and sources of income; others experienced illness - their own or of a relative (Fisher et al., 2020)-, which directly impacted family life. For those who were able to hold jobs, the reality of working from home while assisting with childcare and children's schooling led to added time pressure, vulnerability, anxiety, stress, depression, and burnout (Abdelatiff \& Gatto, 2020; Griffith, 2020; Salari et al., 2020). Single parents, parents of children with disabilities and those from low socioeconomic status and minority groups were placed in a particularly vulnerable position, which may lead to increased inequity and inequality (Abdellatif \& Gatto, 2020; Yoshikawa et al., 2020).

Studies based on data collected between March and June of 2020 confirmed the effects of the pandemic on adult mental health. Twenge and Joiner (2020) compared data from a nationally representative sample of 2,032 American adults in April 2020 with data obtained from the 2018 National Health Interview Study $(N=19,330)$. Respondents from the 2020 sample were three times more likely to fit criteria for moderate to severe mental distress, with the largest differences found for younger adults and those with children. Patrick et al. (2020) found a worsening of parental mental health between March and June in a sample of 1,011 American parents. Similarly, Brown et al. (2020) found elevated levels of stress due to the coronavirus pandemic in their study of 183 American parents. High levels of parental stress are of concern because they can undermine the ability of parents to provide consistent and nurturing care for their children (Yoshikawa et al., 2020) and from engaging in positive parenting (Johnson, 2020). Elevated parental stress caused by the pandemic was also reported in other studies conducted in the United States (Brown et al., 2020; Gassman-Pines et al., 2020), Japan (Hiraoka \& Tomoda, 2020), Italy (Spinelli et al., 2020), Singapore (Chung et al., 2020), and in a comprehensive meta-analysis with a total sample size of 9,074 participants (Salari et al., 2020). Specific to parenting, stress was found to be a mediator between the perceived impact of the coronavirus pandemic and parent-child closeness, and between the impact of COVID-19 and harsh parenting in a study of 258 respondents (Chung et al., 2020). Altogether, these findings are in line with the idea that "stressors that impede the functioning of one family member may lead to change in the functioning of all family members" (Prime et al., 2020). A genuine concern of many scholars and practitioners working with children is an increased risk for harsh parenting and family violence (Bhatia et al., 2020; Humphreys et al., 2020).

The COVID-19 pandemic has also brought parental roles and identities to the fore. Shafer et al. (2020) cautioned that the pandemic could prompt a return to traditional gender roles for heterosexual couples, with women shouldering most of the responsibilities associated with childcare and housework. In their survey of 1,294 Canadian parents in opposite-gender relationships and with children under the age of 18 , the authors found the division of housework to become slightly more equal, although fathers reported more equality in the home than mothers. Feng and Savani (2020) examined job satisfaction and work productivity before and during the lockdown in 300 employed women and men from dual-career families in the United States, who were working from home. They found women, but not men, to report lower levels of job satisfaction and work productivity during the lockdown. In an autoethnography, Abdellatif and Gatto (2020) offered insights into the intersectional and divergent experiences of parents during the pandemic, with contextual stressors shaping their beliefs and behaviors about parenting (see also Coyne et al., 2020), and consequently, their children's wellbeing.

Children and adolescents have been deeply impacted by the effects of the COVID-19 pandemic. According to the Organization for Economic Cooperation and Development (OECD) poverty, disability, homelessness, immigration status, housing quality, access to technology, family violence and home stability are some factors to impact young people during the pandemic (Ramos \& Scarpetta, 2020). At the time of writing, data was beginning to emerge on the experiences of youth during the pandemic from educational, socioeconomic and psychological perspectives. Jiao et al. (2020) found Chinese youth aged 3-18 to experience high levels of fear and uncertainty, along with distraction, irritability, clinginess, and fear or avoidance of talking about the coronavirus. Spinelli et al. (2020) found the effects of quarantine on Italian children's (ages 2-14 years) wellbeing to be mediated by parents' stress levels and negative perceptions of the situation. The negative impact of parental stress on children's wellbeing was found for all age groups in the study, with children from at-risk families being more prone to acting in negative and aggressive ways (Spinelli et al., 2020). Ellis et al. (2020) studied Canadian adolescents' loneliness and depression, and found them to be associated with elevated time spent on social media during the initial months of the pandemic. They also found adolescents who spent more time with family and schoolwork to be less depressed. It is clear from these studies that the pandemic impacted many aspects of children's lives, including their relationships with family members and social media presence. 
Children's out-of-home learning experiences in schools and community programs were also affected by the pandemic. Aside from school shutdowns and transitions to distance learning (e.g., Pramling Samuelsson et al., 2020), extracurricular activities (EAs) were also reduced, modified or canceled, affecting many families. Many American children spend a considerable amount of their out-of-school time in EAs, and this is especially true for children from affluent and educated families (Covay \& Carbonaro, 2010; Lareau, 2011; Meier, Hartmann, \& Larson, 2018). Some have suggested that EAs are "the new knife perforating American communities by social class" (Meier et al., 2018, p. 193), because participation in EAs is intimately linked with parenting styles (Lareau, 2011). While middle class and affluent parents often engage in concerted cultivation, a parenting style that revolves around EAs as a means for children to develop skills that will help them get ahead in an uncertain world; working class parents typically engage in the accomplishment of natural growth, a parenting style that involves meeting the basic needs of love, shelter and care, with EAs playing a less prominent role in family life (Lareau, 2011).

Typically structured and led by adults, EAs are offered in individualized forms or to groups of similar-aged children, in schools and community spaces. Athletics, artistic, and academic are the three main types of EAs (Friedman, 2013), with sports being the most popular for American schoolaged children (Pew Research Center, 2015). Many working parents rely on EAs to assist children with homework, develop specialized skills, and to keep them safe (Adams \& Todd, 2020). Children from different social strata gain cognitive, motor, and socioemotional benefits from participation in EAs (Covay \& Carbonaro, 2010; Ilari et al., 2019; Mahoney et al., 2005; Metsäpelto \& Pulkkinen, 2014). Participation in EAs is also a marker of youth identity, making their reduction or cancellation a stressor for children and families alike.

\section{Conceptual Framework}

Guided by ecological frameworks and systems views of human development (Bronfenbrenner \& Morris, 2006; Lerner \& Damon, 2006), the family stress model (Conger et al., 2002), family systems theory (Carr, 2015), and the family resilience framework (Walsh, 2015), Prime et al. (2020) proposed a conceptual framework on the "cascading effects" of the pandemic on children and families. The framework rests on five main principles. First, children's adjustment to the pandemic is influenced by distal (i.e., the pandemic) and proximal factors such as interactions with family, peers, and teachers (Bronfenbrenner \& Morris, 2006). Contextual issues affect relationships within families and consequently their wellbeing, bearing profound implications for behavioral, social, emotional and cognitive development. Second, the pandemic has affected the social and economic forces that directly impinge on wellbeing, with parents and caregivers experiencing an unprecedented amount of stress. Caregiver wellbeing directly affects the quality of family relationships; high levels of caregiver stress have been linked to the reduction of positive parenting and undesirable outcomes for children (Conger et al., 2002). Third, and consistent with family systems theory (Carr, 2015), stressors that negatively affect one family member are likely to influence functioning in other family members. Understanding how the pandemic affects one or more family members is therefore central to understanding family wellbeing. Fourth, there are key mediating processes within families that influence adaptation to the social disruption caused by the pandemic, in positive and negative ways. These mediating processes are communication, organization and belief systems (Walsh, 2015), and each represents a source of resilience. Fifth, the effects of the pandemic will vary considerably across families. Some families are in a position of higher vulnerability and disadvantage due to poverty, mental health issues, disability and marginalization. Adaptation and resilience are obviously linked to family wellbeing.

The proposed framework is consistent with the research outlined earlier that suggested a profound and complex impact of COVID-19 on the lives of families. Although the negative impact of the pandemic on the human psyche has been recognized (e.g., Yoshikawa et al., 2020), little information is currently available on parental cognitions and behaviors during these challenging times. Such knowledge can offer insights into the lives of families, and assist in the development of future programs and policies to support them. Earlier research suggests that positive parenting and consistent (non-violent) discipline are protective factors against conduct problems in children and youth (e.g., Elgar et al., 2007). Likewise, family rituals and routines (Fiese et al., 2002) and positive relationships at home have been described as central to children's health and wellbeing. In terms of parental beliefs, associations have been found between a nurturing and stimulating child-rearing environment and parenting self-efficacy (Wittkowski et al., 2017), or the perception that one is competent and confident in raising children (Waters \& Sun, 2016). Whereas low levels of parenting self-efficacy have been associated with parental stress and depression, high levels have been linked with positive emotions in parents (Waters \& Sun, 2016).

The aim of this exploratory study was, therefore, to examine parents' perceptions of their own parenting in relationship to six interrelated factors- positive parenting, inconsistent discipline, positive relationships, positive 
Table 1 Description of study participants and their families

\begin{tabular}{|c|c|c|}
\hline Variables & $n$ & $\%$ \\
\hline \multicolumn{3}{|l|}{ Parent } \\
\hline Mother & 104 & 87.4 \\
\hline Father & 15 & 12.6 \\
\hline \multicolumn{3}{|l|}{ Age } \\
\hline $21-30$ & 1 & 0.9 \\
\hline $31-40$ & 47 & 42.7 \\
\hline $41-50$ & 58 & 52.7 \\
\hline $51-60$ & 4 & 3.6 \\
\hline \multicolumn{3}{|l|}{ Education } \\
\hline High School & 4 & 3.4 \\
\hline College degree & 31 & 26.1 \\
\hline Master's degree & 48 & 40.3 \\
\hline Doctoral degree & 36 & 30.3 \\
\hline \multicolumn{3}{|l|}{ Work status } \\
\hline Working from home & 94 & 79 \\
\hline Not working from home & 25 & 21 \\
\hline \multicolumn{3}{|l|}{ Employment areas } \\
\hline Education (all levels) & 44 & 36.9 \\
\hline Business \& Administration & 26 & 21.8 \\
\hline Health & 16 & 13.4 \\
\hline Science \& Engineering & 5 & 4.2 \\
\hline Arts & 7 & 5.8 \\
\hline Law & 1 & 0.8 \\
\hline Homemaker & 14 & 11.7 \\
\hline Graduate student & 6 & 5 \\
\hline \multicolumn{3}{|l|}{ People living at home } \\
\hline One or more children $<5$ years & 45 & 16.7 \\
\hline One or more children $5-12$ years & 83 & 30. \\
\hline One of more adolescent/young adult & 29 & 10.8 \\
\hline Other parent/partner & 100 & 37.4 \\
\hline Grandparents & 7 & 2.6 \\
\hline Other & 4 & 1.5 \\
\hline
\end{tabular}

emotions, self-efficacy, and routine management- , and to learn about parent-child activities in American families with children aged 0-16 years, following measures of social distancing. Specifically, we examined whether parental roles, age, and perceptions of work productivity had any influence on perceptions of parenting during the initial months of the pandemic. Because engagement in EAs is a central feature of American family life and parenting (Lareau, 2011), we also gauged hours of participation, and types of activities that children took part in (before and after social distancing was mandated). Additionally, parents were asked to share impressions of parenting and parent-child relationships during the initial months of the coronavirus pandemic.

\section{Method}

\section{Participants}

Parents aged between 21 and 60 years with at least one child aged 0-16 years were recruited through posts on Englishlanguage parent online groups on Facebook. One hundred and eighty-six parents began the survey, yet their data were not included in the final analysis if they answered less than $75 \%$ of the questions $(n=38)$, or resided outside of the United States $(n=29)$. The final sample included 119 American parents (104 mothers). Most parents $(n=99)$ were living with their spouses or partners, one respondent was in a non-binary relationship, and 19 were single parents. The number of people residing in the respondents' homes varied between two and $10(M=3.60, \mathrm{SD}=1.25)$. This was an educated sample, with most parents holding graduate degrees. Two parents reported that they had been quarantined at home for approximately one week (in a foreign country), and only $3.4 \%$ had children who were being homeschooled before social distancing was mandated. Time observing social distance varied between 0 and 20 weeks $(M=9$ weeks). Most parents $(79 \%)$ were working from home at the time of data collection and rated their work productivity as moderate on a scale of $1-5$ (mode $=3)$. Chi-square tests indicated that there were no significant differences between mothers and fathers in terms of age $\left(\chi^{2}=0.85, \mathrm{df}=1, p=0.35\right)$, education levels $\left(\chi^{2}=3.30, \mathrm{df}=3, p=0.34\right)$, and perceptions of work productivity $\left(\chi^{2}=1.85, \mathrm{df}=5, p=0.86\right)$. Table 1 offers a full description of study participants.

This study was approved by the Institutional Review Board (IRB) of the University of Southern California (protocol UP 20-00287). The authors developed an anonymous, online questionnaire that was distributed through Qualtrics between May 8 and June 28, 2020. The questionnaire was divided into six main sections: (1) demographics, (2) parental work and perceived time spent in childcare; (3) perceptions of parenting during the pandemic, (4) extracurricular activities; (5) parent-child activities; and (6) open-ended reflections on parenting during the pandemic.

\section{Demographics}

Parents were asked to provide information on parental roles (mother, father, other), age, education, occupation, and number of people residing in the home. They were also asked to indicate if this was their first time practicing social distancing/being in a lockdown.

\section{Parental Work, and Perceived Time Spent in Childcare}

Parents were asked to inform if they were working from home (dichotomous: yes, no) and if they responded "yes," 
to rate their work productivity using a scale of $1-5(1=$ not productive at all, $5=$ extremely productive). Parents also estimated their involvement in childcare, before and after social distancing was mandated, on a scale of 1-5 $(1=100 \%$ of the time, $2=75 \%, 3=50 \%, 4=25 \%$, and $5=0 \%$ ).

\section{Perceptions of Parenting During the Pandemic}

Parents rated 21 statements on a 5-point scale in terms of frequency of occurrence $(1=$ never, $5=$ always $)$, using the last $48 \mathrm{~h}$ as a guide. These statements were grouped into six interrelated categories that emerged from a review of extant research: Positive parenting, inconsistent discipline, positive relationships, positive emotions, self-efficacy, and routine management. The first two categories, positive parenting and inconsistent discipline, were modeled after the Alabama Parenting Questionnaire - Short Form (Elgar et al., 2007). Positive parenting included three statements referring to praise and compliment (e.g.."You compliment your child/children if they have done something well"). Inconsistent discipline referred to parental use of discipline with children (e.g., "You let your child out of a punishment early"). Positive relationships measured parental roles in modeling and fostering positive interactions between the child and one or more family members through three statements (e.g., "You talk to your child"). Positive emotions was based on three statements about parents' emotional states at the time of data collection (e.g., "You feel in control; you do not feel overwhelmed"). Parenting selfefficacy was gauged through four statements that focused on beliefs and confidence in one's parenting skills (e.g., "You feel confident about homeschooling your child"). Finally, routine management was related to parents' management of children's daily activities through two statements (e.g., "You control your child's screen time and contents").

\section{Extracurricular Activities}

Parents reported the number of hours that children spent weekly on EAs, and listed all activities in which their children were involved, before and after social distancing was mandated. These included "in person" and virtual activities.

\section{Parent-Child Activities}

Parents ranked their most and least liked activities to do with children at home, and also reported which activities they were engaged in at the time of data collection.

\section{Parental Reflections}

Parents were invited to answer two final open-ended questions:
1. In what ways (if any) has the experience of social distancing changed your relationship with your child/ children?

2. Is there anything else that you would like to share about your parenting experiences during the mandated period of social distancing?

Completion of the questionnaire took approximately $15 \mathrm{~min}$. Parents were allowed to skip any question that they did not wish to answer.

\section{Data Analysis}

Means and standard deviations were calculated for all variables. Time spent in childcare was measured at the ordinal level, therefore we ran a Wilcoxon signed-ranks test to determine the difference between estimates of time spent in childcare before and after safer-at-home measures. One-way MANOVAs were performed to analyze parental role, education and age, and perceptions of work productivity on parents' ratings of the six categories. Reliability for each parenting component was calculated using Cronbach's alpha (Table 2). A paired-sample t-test was used to compare the number of extracurricular activities before and after safer-at-home measures were put in place. All statistical analysis were performed on SPSS software $\left(27^{\text {th }}\right.$ version). The two open-ended questions (item 6) were analyzed using content analysis (Hsieh \& Shannon, 2005). Because there were many overlaps in parental answers to these two questions, responses were juxtaposed and categorized by their main themes and emotional valence (i.e., whether they were positive, negative or "bittersweet"). Emotionally neutral responses and those that did not fit into the three categories were listed under "other". Two independent judges analyzed all responses and agreed on their categorization in $85 \%$ of the cases. The remaining $15 \%$ of cases were discussed by the two judges with the assistance of a third judge until $100 \%$ of agreement was achieved.

Table 2 Descriptive data

\begin{tabular}{llll}
\hline Variables & Mean & SD & Cronbach's alpha \\
\hline Work productivity at home & 3.41 & 1.99 & - \\
Positive parenting & 4.36 & 0.55 & 0.87 (3 items) \\
Inconsistent discipline & 2.41 & 0.79 & 0.68 (3 items) \\
Routine management & 3.64 & 0.83 & $0.55(2$ items $)$ \\
Positive relationships & 3.91 & 0.51 & $0.48(3$ items $)$ \\
Positive emotions & 3.05 & 0.70 & $0.70(3$ items $)$ \\
Self-efficacy in parenting & 3.69 & 0.60 & $0.56(4$ items $)$ \\
Composite (total) & 3.51 & 0.33 & \\
\hline
\end{tabular}


Fig. 1 Children's extracurricular activities before and after "saferat-home" measures

\section{Extracurricular activities}

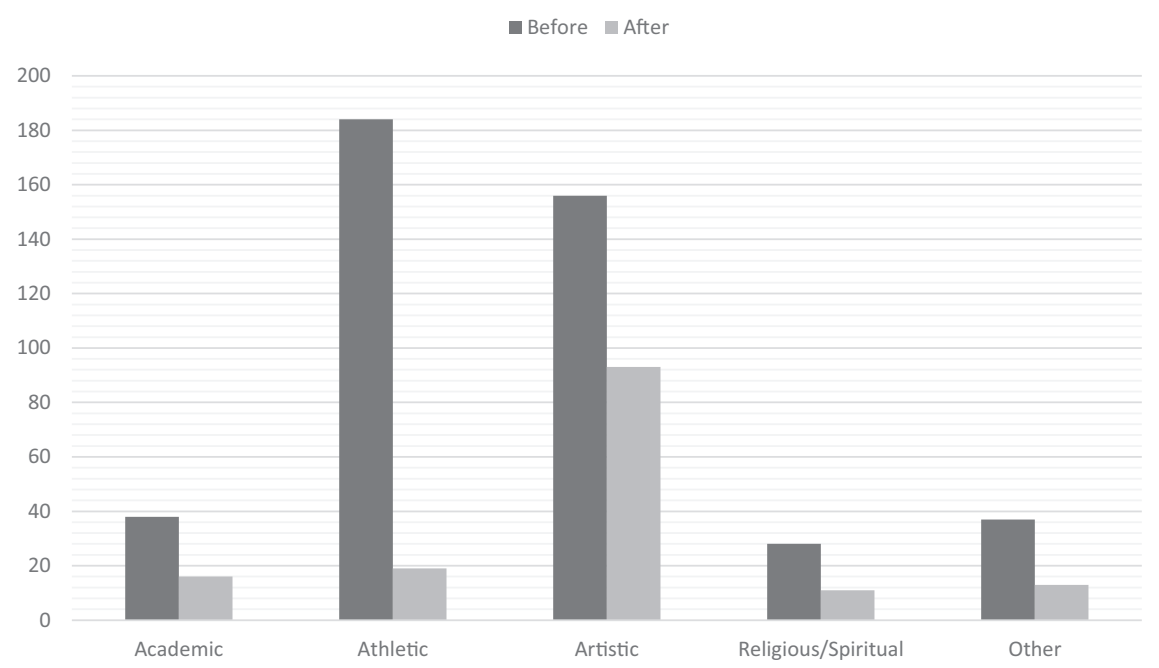

\section{Findings}

A first question of interest to this study was parental perceptions of work productivity at home, and time spent in childcare before and after social distancing was mandated. Parents rated their work productivity as moderate $(M=3.41$, $\mathrm{SD}=1.99)$. In terms of time spent in childcare, all parents scored lower after social distancing was mandated. Results indicated that perceived time spent in childcare before social distancing was mandated (mean rank $=2.5$ ) was rated more favorably than perceived time spent in childcare after social distancing was mandated (mean rank $=2.3$ ), $z=-3.2, p=$ 0.001 . This indicates that parents became more involved in childcare following measures of social distancing.

In terms of perceptions of parenting during the pandemic, a one-way MANOVA indicated that there were no significant differences between mothers' and fathers' ratings for all six categories, $F(6,110)=1.39, p=0.23$, Wilks' Lambda $=0.93$. Likewise, there were no significant differences between younger (under 40 years) and older parents' (over 40 years) ratings for the six parenting categories, $F$ (6, $112)=1.73, p=0.12$, Wilks' Lambda $=0.92$, and no significant difference between parents' responses to the six categories based on their education levels, $F(18,311.61)=$ $1.43, p=0.11$, Wilks' Lambda $=0.80$. However, a oneway MANOVA indicated that there was a significant difference between parental perceptions of parenting as a function of their productivity, $F(24,301.23)=2.11 p=$ 0.002 , Wilk's Lambda $=0.58$, partial eta squared $=0.13$. Parents' work productivity accounted for $13 \%$ of the variance of their perceptions of parenting, a medium effect size (Cohen, 1988). Mean scores were statistically different for the category positive emotions, $F(4,91)=9.57, p \leq 0.001$, partial eta squared $=0.30$, a large effect size (Cohen, 1988).
Tukey post-hoc tests indicated that parents who rated themselves very high on work productivity reported higher scores for positive emotions (i.e., finding time for oneself, balancing everyone's needs, and feeling in control) than parents who rated their productivity as moderate (score $=$ $3, p=0.001$ ), low (score $=2, p<0.001$ ), and very low (score $=1 ; p<0.001)$. Perceptions of productivity and parental self-ratings for positive emotions were also highly correlated, Pearson $r=0.526, p<0.001$, two-tailed. These findings suggest that work productivity may have functioned as a source of resilience for participating parents.

Another variable of interest was children's participation in EAs. Before social distancing was mandated, children spent an average of 5.6 weekly hours (range $=0.5-14 \mathrm{~h}$, $\mathrm{SD}=4.89$ ) involved in EAs. With the shutdown of schools and services, the number of hours that children spent in EAs went down to 1.8 hours (range $=0 \mathrm{~min}-3.5 \mathrm{~h}$, $\mathrm{SD}=2.30$ ). A paired-sample $t$-test revealed that this difference was statistically significant, $t(92)=7.880, p<$ 0.001 , two-tailed. The total number of EAs across all study participants went down from 443 to 152 after safer-athome measures were put in place. To get a better sense of how the pandemic affected children's EA participation, parental entries were categorized into five main categories: academic, artistic, athletic, religious, and "others" (Fig. 1). Whereas athletic activities suffered the largest reduction overall (almost 90\%), artistic activities suffered the least (approximately 40\%). Academic, religious and "other" EAs were somewhere in the middle with reductions of $50 \%, 61 \%$, and $65 \%$, respectively. Within each category, the activities that suffered the smallest reduction after social distancing measures were put in place were language courses $(7$ entries at both time points $=$ no reduction), music lessons (from 64 to 59 entries $=$ reduction of 
approximately $8 \%$ ), martial arts (from 21 to 5 entries = reduction of $76 \%$ ), religious/spiritual activities (from 28 to 11 entries = reduction of approximately 61\%), and "others"-scout groups (from 20 to $7=$ reduction of $65 \%$ ). Parents indicated that collective sports (e.g., soccer, basketball, baseball), gymnastics, and volunteer work were canceled or became unavailable when measures of social distancing were put in place.

Unsurprisingly, nearly $80 \%$ of parents reported that they were spending more time engaged in various activities with their children as well as searching for more activities to do with them (approximately 61\%) than before the pandemic. When asked about parent-child activities at home (Fig. 2), parents' most liked activities were cooking and baking, playing board games or with toys, watching films and TV, music and reading. Academic activities, homework, videogames and social media featured as parents' least liked activities to do with children. Still, most parents reported that they were helping with homework and reading with their children (Fig. 2).

At the end of the questionnaire, parents were also invited to share any thoughts about the experience of social distancing and their relationship with children, and anything else that they wished to share. As seen in Table 3, parental responses yielded 327 entries that were categorized based on their theme and emotional valence. Answers were distributed as follows: positive $(n=158)$, negative $(n=115)$, bittersweet $(n=28)$, and "other" $(n=26)$.

\section{Discussion}

In this exploratory study we used self-reports to gauge perceptions of parenting by American mothers and fathers with children under 16 years of age. Data were collected between 8 and 16 weeks after the World Health Organization declared COVID-19 a pandemic. Three main findings emerged from our study. First, we found that participating parents were spending more time involved in childcare after safer-at-home measures were put in place. This has been reported in other studies (Feng \& Savani, 2020) and is not surprising given the blurring of the lines between home, school and work that followed the implementation of measures of social distancing in many cities and states. Due to the unpredictability of infections, virus variants, vaccination rates, everchanging safety measures, work policies, and the provision (or lack thereof) of services to children and families during these trying times, future studies should revisit this question. It is also vital to interrogate the extent to which parents (and mothers in particular) have been forced to leave the workforce to care for children at home, as reported in the popular press (Gupta, 2020). Moreover, there is a pressing need for policies that support working parents, including in times of crisis.

A second main finding was that parents who rated themselves high in work productivity rated themselves higher for positive emotions than those who rated themselves as moderately or not productive following measures of social distancing. This finding may reflect the association between work productivity and wellbeing, which has been documented

\section{Parent-child activities in the home}

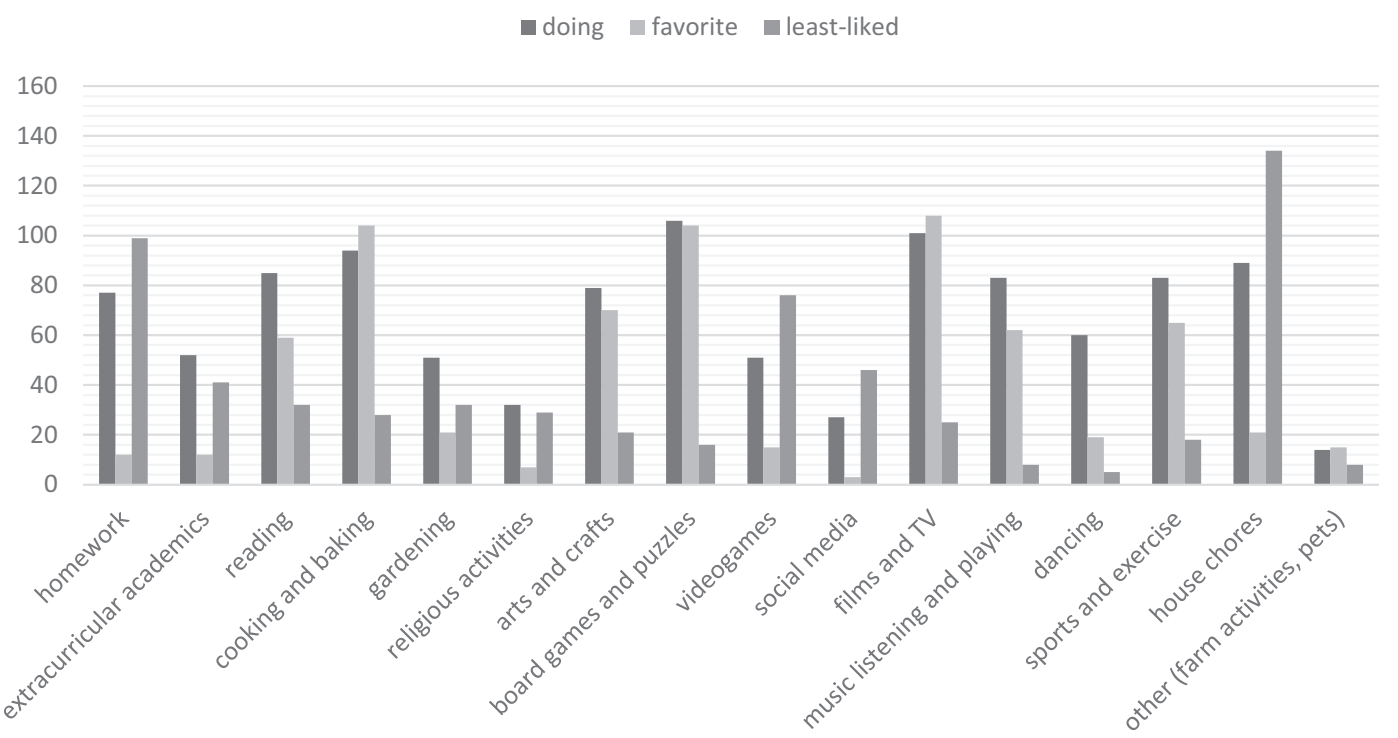

Fig. 2 Parent-child activities in the home, favorites and least-liked 
Table 3 Themes from openended questions

\begin{tabular}{|c|c|c|c|}
\hline Theme & Count & Percentage & Quotes \\
\hline \multicolumn{4}{|l|}{ Positive elements } \\
\hline $\begin{array}{l}\text { Spending more time } \\
\text { together }\end{array}$ & 56 & 17.1 & \multirow[t]{2}{*}{ We spend more time cuddling. } \\
\hline $\begin{array}{l}\text { Strengthening parent- } \\
\text { child bonds }\end{array}$ & 52 & 15.9 & \\
\hline $\begin{array}{l}\text { Learning more about } \\
\text { each other }\end{array}$ & 27 & 8.2 & \multirow[t]{2}{*}{ We have learned to be more patient with each other. } \\
\hline $\begin{array}{l}\text { Parents more attuned to } \\
\text { children's schooling }\end{array}$ & 6 & 1.8 & \\
\hline $\begin{array}{l}\text { Child learning valuable } \\
\text { life lessons }\end{array}$ & 4 & 1.2 & \multirow{5}{*}{$\begin{array}{l}\text { Less running to and from activities (and a husband who } \\
\text { is usually out of town } 75 \% \text { of the time) means more } \\
\text { family dinners and meaningful moments. }\end{array}$} \\
\hline $\begin{array}{l}\text { Child more independent } \\
\text { and helpful }\end{array}$ & 7 & 2.1 & \\
\hline Better routines at home & 3 & 0.9 & \\
\hline Less running around & 3 & 0.9 & \\
\hline TOTAL & 158 & 48.3 & \\
\hline \multicolumn{4}{|l|}{ Negative elements } \\
\hline Balancing childcare/work & 19 & 5.8 & \multirow{3}{*}{$\begin{array}{l}\text { Discipline has become an issue because our child acts up } \\
\text { more than prior to social distancing. }\end{array}$} \\
\hline $\begin{array}{l}\text { Stress, exhaustion, } \\
\text { impatience }\end{array}$ & 35 & 10.7 & \\
\hline $\begin{array}{l}\text { Many challenges at once, } \\
\text { like keeping a routine }\end{array}$ & 21 & 6.4 & \\
\hline $\begin{array}{l}\text { Concerns with child's } \\
\text { social and emotional } \\
\text { wellbeing }\end{array}$ & 8 & 2.4 & \multirow[t]{3}{*}{$\begin{array}{l}\text { I am sick of them. My spouse works and I am in charge } \\
95 \% \text { of the day. I am exhausted. }\end{array}$} \\
\hline $\begin{array}{l}\text { Bored, depressed, clingy } \\
\text { children }\end{array}$ & 14 & 4.2 & \\
\hline $\begin{array}{l}\text { Conflicts due to overuse } \\
\text { of screens }\end{array}$ & 5 & 1.5 & \\
\hline Health concerns & 2 & 0.6 & \multirow{3}{*}{$\begin{array}{l}\text { I am working with COVID patients, so I have fears of } \\
\text { bringing the virus to my children. }\end{array}$} \\
\hline Other & 11 & 3.3 & \\
\hline TOTAL & 115 & 35.1 & \\
\hline $\begin{array}{l}\text { Bittersweet TOTAL } \\
\text { (positive and negative) }\end{array}$ & 28 & 8.5 & $\begin{array}{l}\text { While the joy of spending time with my kids is greater, so } \\
\text { is the frustration as I'm doing the majority of the } \\
\text { childcare, homework help, household chores, all while } \\
\text { working from home. }\end{array}$ \\
\hline Other - No change & 9 & 2.7 & \multirow{3}{*}{$\begin{array}{l}\text { Stay at home and enjoy the time of being with your } \\
\text { children! }\end{array}$} \\
\hline $\begin{array}{l}\text { Other - words of advice; } \\
\text { random }\end{array}$ & 17 & 5.2 & \\
\hline Other - TOTAL & 26 & 7.9 & \\
\hline
\end{tabular}

in the literature (Krekel et al., 2019). It is also possible that parental productivity was related to parental perceptions of job security during uncertain times. A focus on work might have shielded some parents from negative thoughts and emotions as they worked from home, functioning as a source of resilience. Regarding the other five parenting categories, it was noteworthy how positive parenting and positive relationships received the highest ratings, while positive emotions and inconsistent discipline received the lowest ones. These findings offer an interesting portrait of parental cognitions during the initial months of the pandemic, with parents being generally positive about their behaviors and attitudes, whilst exhibiting a mixture of positive and negative emotions, as seen in their responses to the open-ended questions. As we continue to live through the effects of COVID-19, future studies could revisit parental cognitions and behaviors to determine whether they have changed, and if so, in which direction and what potentially caused such changes. Such 


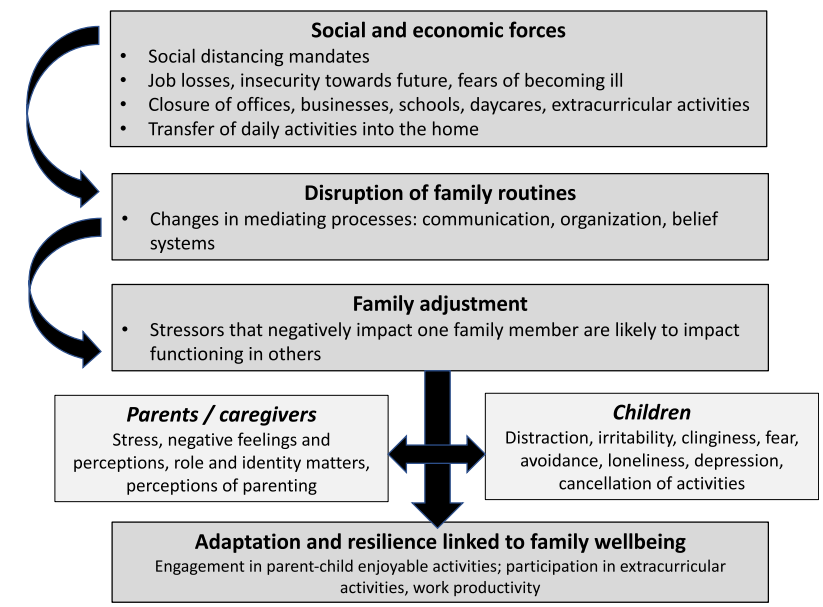

Fig. 3 Cascading effects of the pandemic in light of current research and findings from this study.

findings are relevant for those working with families in educational and clinical settings.

A third main finding relates to the significant reduction of children's EAs following safer-at-home measures. It was interesting to note how artistic activities (e.g., music) were the ones suffering the least amount of reduction once social distancing measures became the norm. At a first glance, one could argue that these activities were maintained due to their individual or "one-on-one" nature and quick adaptability to virtual spaces, although this is far from the truth. Collective artistic activities like drama and dance also suffered a comparatively smaller reduction than individual sports (e.g., tennis, swimming lessons), some academic programs (e.g., science), and other activities (e.g., gaming). Within athletic activities, collective martial arts like karate, judo and jiu-jitsu were the ones that suffered the least amount of reduction. Perhaps these activities were able to continue due to their associations with self-expression, emotional communication, mindfulness, and wellbeing (Croom, 2014). This explanation is consistent with recent works documenting the use of music (Corvo \& DeCaro, 2020) and martial arts (Lindell-Postigo et al., 2020) to promote wellbeing during the initial months of the pandemic. It is also possible that some of these activities were able to continue due to their transferability, instructor technological skills and access to digital platforms. That music lessons suffered minimal interruption is intriguing, given the issue of latency associated with sound transmission through virtual platforms.

Still, this significant reduction in children's participation in EAs raises questions regarding the future of concerted cultivation as a popular, middle-class parenting style in American families (Lareau, 2011). Comments such as "we are really missing sports, dance and other social/teamwork experiences" or "it is challenging to find replacement activities, especially for physical activities and social interactions for young children, as through collaborative music and other forms of play with peers" confirmed the pervasiveness of extracurricular activities in the lives of surveyed families. Although some EAs have become available (e.g., swimming, gymnastics) in some modified fashion and following safety protocols, parents continue to show concerns with children's reduced or lack of access the EAs during the pandemic (Pew Research Center, 2020). While EAs were reduced during the initial months of the pandemic, multiple learning pods (i.e., small groups of children learning together out-of-school, but still in person, with a teacher or parent, see Blum \& Miller, 2020) emerged during that time, along with the migration of middle-class families from public to private schools, especially those that offered in person learning (Reilly, 2020). Such practices represented an obvious parental effort to mitigate the effects of social distancing on their children's learning. But as Adams and Todd (2020) pointed out, the costs associated with such practices are beyond the means of most families, and may impact children's achievement. They may also contribute to the increase of structural inequalities in the near future. Whether changes in parental demands and preferences for children's education, along with adaptations to EAs will continue in the post-pandemic era remains to be determined. Yet it is clear is that these changes will affect educational practices and policy in schools, after-school and recreational programs in the near future.

Parent-child activities revealed in our data are also worthy of commentary. It was interesting to see contrasts between parents' most and least-liked activities, as well as with the activities that they were actually engaged in with their children. Most parents reported that they disliked doing homework and academic activities with their children, yet did them anyway. Since many children are undergoing distance learning (or online) programs-a practice that requires a considerable amount of parental involvement (see Wang, 2020)_-, this finding should not be ignored. Parents may not feel confident or know how to best support their children with academic activities and homework (Parcewska, 2020). Therefore, there is an urgent need for parental support in these areas, particularly if COVID-19 persists for much longer.

Consistent with Prime et al.'s (2020) conceptual framework, the social, economic and psychological effects of COVID-19 were evident in parental responses. Work productivity appeared to be a source of adaptation and resilience for participating parents, given its association with higher ratings of positive emotions (i.e., an indicator of parental wellbeing). Likewise, our data hints at the idea that engagement in preferred activities and children's 
participation in extracurricular activities after safer-at-home measures were in place might have promoted a sense of "normalcy" and wellbeing, functioning as another source of resilience. By the same token, the cancellation of EAs was likely a source of stress for participating youth. Figure 3 offers an illustration of the cascading effects of the pandemic (Prime et al., 2020) in light of the studies reviewed earlier and our three main findings.

Finally, the effects of the pandemic were reflected in parents' intricate responses to the open-ended questions. While we did not find statistically significant differences between the ratings of mothers and fathers on perceived time spent in childcare, a more nuanced picture emerged in the qualitative responses (including some that appeared earlier in this article), hinting at a potential reversal of traditional gender roles (Feng \& Savani, 2020; Shafer et al., 2020). As one mother stated:

I've recently gone back to clinical work and landed a dream job. I've been part-time as I want to remain with my kiddos as they are young. When I work, my mom provides childcare. And not only do my husband and I miss her help, but also my kids are beside themselves. Even with daily FaceTime chats, the most asked question is, "When can I see my Grammy?" I knew their relationship with her was special, but they are grieving the loss of physical contact with her. And that's powerful. As well, our state is opening up despite warnings. My husband will likely go back to work soon, which means that I may have to quit my dream job to take care of the kids. There is no childcare available and I will not risk my 70-year-old mom's health and wellbeing. Even with the blessings and privilege my family has, there are tough financial and health decisions to be made. I cannot imagine what others, who may have no options, are experiencing.

As this response suggests, the pandemic is having a cascading effect on the family as purported by Prime et al. (2020). A complex picture of parenting behaviors and cognitions during the pandemic emerged from our data, suggesting that families were quickly adapting to a new reality. Our findings also concur with the need to develop new policies that support working parents and families, as they pertain to work, home life, caregiving support, schooling and extracurricular activities (Adams \& Todd, 2020; Wang, 2020). At the time of writing, a new set of policy actions with regards to working with children and families was beginning to emerge. In educational settings, for example, some districts offered professional development on family life for teachers who had been working closer than ever with families. Continuous professional development in areas concerning families and parenting is recommended for teachers and other professionals working with children and youth. We also suggest the incorporation of courses on parenting and family life in pre-service teacher education and related fields. Such practices along with new policies will hopefully alleviate some stressors caused by the pandemic and contribute to the wellbeing of parents, children and communities, now and once this challenging historical moment is over.

\section{Limitations and Future Research}

The present study is not without limitations. The sample was relatively small and consisted of a group of parents who had access to technology, time and interest in parenting. We recognize that the age range of 0-16 years is wide, as our purpose was to offer an overview. Because parenting is known to change over time, as children develop and grow in culture, future studies could focus on a narrower age range. Consistent with recent parenting surveys (e.g., Mantovani et al., 2021), most respondents in this study were mothers. Furthermore, we did not ask parents to report their ethnicity, race or income, nor did we gather information about their geographical location within the United States. Future studies could take these issues into account, and target more specific participants and groups.

Another issue to consider is that of time. While the pandemic is a global event that signals the macro-time and the Zeitgeist, data from this study illustrates the micro-time, or "in the moment" events (Bronfenbrenner \& Morris, 2006). The constant changes associated with mandates of social distancing, the uncertainties brought about by the pandemic, vaccination rates, and the dynamic nature of parenting and family life reinforce the idea that any parenting study conducted during the pandemic is time sensitive. By surveying parents at different points in time, researchers will get a clearer picture of the cascading effects of the pandemic on children and families, as well as ways to counter them through strong policies and programs.

\section{Compliance with Ethical Standards}

Conflict of Interest The authors declare no competing interests.

Informed Consent The survey and methodology for this study was approved by Institutional Review Board (IRB) of the University of Southern California (protocol UPC: 20-00287). Participants gave their consent by answering the anonymous survey. An information sheet was provided along with the online survey, in compliance with the regulations of USC's IRB.

Publisher's note Springer Nature remains neutral with regard to jurisdictional claims in published maps and institutional affiliations.

\section{References}

Abdellatif, A., \& Gatto, M. (2020). It's ok to not be ok: Shared reflections from two $\mathrm{PhD}$ parents in a time of pandemic. Gender 
and Work Organization, 27(5), 723-733. https://doi.org/10.1111/ gwao.12465.

Adams, G., \& Todd, M. (2020). Meeting the school-age child care needs of working parents facing COVID-19 distance learning: Policy options to consider (Working Paper). Urban Institute. https://www.urban.org/research/publication/meeting-school-agechild-care-needs-working-parents-facing-covid-19-distance-lea rning.

Bhatia, A., Fabbri, C., Cerna-Turiff, I., Tanton, C., Knight, L., Turner, E., Lokot, M., Lees, S., Cislaghi, B., Peterman, A., Guedes, A., \& Devries, K. (2020). COVID-19 response measures and violence against children. Bulletin of the World Health Organization, 98, 583-583A. https://doi.org/10.2471/BLT.20.263467.

Blum, S., \& Miller, F. (2020, August 18). What parents need to know about learning pods. The New York Times. https://www.nytimes. com/article/learning-pods-coronavirus.html.

Bronfenbrenner, U., \& Morris, P. A. (2006). The bioecological model of human development. In W. Damon \& R. N. Lerner (Eds.), Handbook of child psychology: Theoretical models of human development (5th ed., pp. 993-1027). Wiley \& Sons.

Brown, S., Doom, J. R., Lechuga-Peña, S., Watamura, S. E., \& Koppels, T. (2020). Stress and parenting during the global COVID-19 pandemic. Child Abuse \& Neglect, 110. Advance online publication. https://doi.org/10.1016/j.chiabu.2020.104699.

Carr, A. (2015). The evolution of systems theory. In T. L. Sexton \& J. Lebow (Eds.), Handbook of family therapy (pp. 13-29). Routledge. https://doi.org/10.4324/978203123584-2.

Chung, G., Lanier, P., \& Ju, P. W. Y. (2020). Mediating effects of parental stress on harsh parenting and parent-child relationship during Coronavirus (COVID-19) pandemic in Singapore. Journal of Family Violence. Advance online publication. https://doi.org/ 10.31219/osf.io/vnf4j.

Cohen, J. (1988). Statistical power analysis for the behavioral sciences (2nd ed.). Hillside, NJ: Lawrence Erlbaum Associates.

Conger, R. D., Wallace, L. E., Sun, Y., Simons, R., McLoyd, V., \& Brody, G. H. (2002). Economic pressure in African American families: A replication and extension of the family stress model. Developmental Psychology, 38(2), 179-193. https://doi.org/10. 1037/0012-1649.38.2.179.

Corvo, E., \& DeCaro, W. (2020). COVID-19 and spontaneous singing to decrease loneliness, improve cohesion, and mental well-being: An Italian experience. Psychological Trauma: Theory, Research, Practice, and Policy, 12(S1), S247-S-248 https://doi.org/10.1037/ tra0000838.

Covay, E., \& Carbonaro, W. (2010). After the bell: Participation in extracurricular activities, classroom behavior, and academic achievement. Sociology of Education, 83(1), 20-45. https://doi. org/10.1177/0038040709356565.

Coyne, L. W., Gould, E. R., Grimaldi, M., Wilson, K. G., Baffuto, G., \& Biglan, A. (2020). First things first: Parent psychological flexibility and self-compassion during COVID-19. Behavior Analysis in Practice. Advance online publication. https://doi.org/ 10.1007/s40617-020-00435-w

Croom, A. M. (2014). Embodying martial arts for mental health: Cultivating psychological well-being with martial arts practice. Archives of Budo Science of Martial Arts and Extreme Sports, 10, 59-70.

Elgar, F. J., Waschbusch, D. A., Dadds, M. R., \& Sigvaldson, N. (2007). Development and validation of a short form of the Alabama Parenting Questionnaire. Journal of Child and Family Studies, 16, 243-259. https://doi.org/10.1007/s10826-006-90825 .

Ellis, W. E., Dumas, T. M., \& Forbes, L. M. (2020). Physically isolated but socially connected: Psychological adjustments and stress among adolescents during the initial COVID-19 crisis. Canadian Journal of Behavioural Science / Revue canadienne des sciences du comportement, 52(3), 177-187. https://doi.org/10.1037/ cbs0000215.

Feng, Z., \& Savani, K. (2020). COVID-19 created a gender gap in perceived work productivity and job satisfaction: implications for dual-career parents working from home. Gender in Management: An International Journal, 35(7\&8). https://www.emerald.com/ insight/1754-2413.htm.

Fiese, B. H., Tomcho, T. J., Douglas, M., Joseph, K., Poltrock, S., \& Baker, T. (2002). A review of 50 years of research on naturally occurring family routines and rituals: Cause for celebration? Journal of Family Psychology, 16, 381-390. https://doi.org/10. 1037/0893-3200.16.4.381.

Fisher, J., Languilaire, J., Lawthom, R., Nieuwenhuis, R. J. P., Runswick-Cole, K., \& Yerkes, M. A. (2020). Community, work, and family in times of COVID-19. Community, Work and Family, 23(3), 247-252. https://doi.org/10.1080/13668803.2020. 1756568.

Friedman, H. L. (2013). Playing to win: Raising children in a competitive culture. University of California Press.

Furedi, F. (2001). Paranoid parenting: Why ignoring the experts may be best for your child. Bloomsbury.

Gassman-Pines, A., Aranat, E. O., \& Fitz-Henley, J. (2020). COVID19 and parent-child psychological well-being. Pediatrics, 146(4). https://doi.org/10.1542/peds.2020-007294.

Griffith, A. K. (2020). Parental burnout and child maltreatment during the COVID-19 pandemic. Journal of Family Violence. Advance online publication. https://doi.org/10.1007/s10896-020-00172-2.

Gupta, A. H. (2020, October 3). Why did hundreds of thousands of women drop out of the work force? The New York Times. https://www.nytimes.com/2020/10/03/us/jobs-women-droppingout-workforce-wage-gap-gender.htm.

Hiraoka, D., \& Tomoda, A. (2020). The relationship between parenting stress and school closures due to the COVID-19 pandemic. Psychiatry and Clinical Neurosciences, 74(9), 497-498. https:// doi.org/10.1111/pen.13088.

Hsieh, H. F., \& Shannon, S. E. (2005). Three approaches to qualitative content analysis. Qualitative Health, 15(9), 1277-1288. https:// doi.org/10.1177/1049732305276687.

Humphreys, K. H., Myint, M. T., \& Zeanah, C. H. (2020). Increased risk for family violence during the COVID-19 pandemic. Pediatrics, 146(1). https://doi.org/10.1542/peds.2020-0982.

Ilari, B., Perez, P., Wood, A., \& Habibi, A. (2019). The role of community-based music and sports programs on parental views of children's social skills and personality. International Journal of Community Music, 12(1), 35-56. https://doi.org/10.1386/ijcm. 12.1.35_1.

Johnson, B. (2020). Importance of positive parenting during the pandemic. BMH Medical Journal, 7(3), 46-49. https://www.ba bymhospital.org/BMH_MJ/index.php/BMHMJ/article/view/279.

Jiao, W. Y., Wang, L. A., Liu, J., Fang, S. F., Jiao, F. Y., \& PettoelloMantovani, M. (2020). Behavioral and emotional disorders in children during the COVID-19 epidemic. The Journal of Pediatrics, 221, P264-266E1. https://doi.org/10.1016/j.jpeds.2020.03. 013.

Kagan, S. L. (Ed.). (2019). The early advantage 2: Building systems that work for young children. Teachers College Press.

Krekel, C., Ward, G., \& de Neve, J. E. (2019). Employee well-being, productivity, and firm performance: Evidence and case studies. Global Happiness and Wellbeing Policy Report, 73-94. https://ha ppyfityou.co/pdf/GHWPR19.pdf\#page $=99$.

Lareau, A. (2011). Unequal childhoods. University of California Press.

Lerner, R. M., \& Damon, W. E. (2006). Handbook of child psychology: Vol.1. Theoretical models of human development (6th ed.). Wiley \& Sons.

Lindell-Postigo, D., Zurita-Ortega, F., Ortiz-Franco, M., \& GonzálezValero, G. (2020). Cross-sectional study of self-concept and 
gender in relation to physical activity and martial arts in Spanish adolescents during the COVID-19 lockdown. Education Sciences, 10, 210. https://doi.org/10.3390/edusci10080210.

Mahoney, J. L., Larson, R., Eccles, J., \& Lord, H. (2005). Organized activities as contexts of development: Extracurricular activities, after-school and community programs. Lawrence Erlbaum.

Mantovani, S., Bove, C., Ferri, P., Manzoni, P., Cesa Bianchi, A., \& Picca, M. (2021). Children "under lockdown"” Voices, experiences, and resources during and after the COVID-19 emergency. Insights from a survey with children and families in the Lombardy region of Italy. European Early Childhood Education Research Journal, 29(1), 35-50. https://doi.org/10.1080/ 1350293X.2021.1872673.

Meier, A., Hartmann, B. S., \& Larson, R. (2018). A quarter century of participation in school-based extracurricular activities: Inequalities by race, class, gender and age? Journal of Youth \& Adolescence, 47, 1299-1316. https://doi.org/10.1007/s10964-018-0838-1.

Metsäpelto, R., \& Pulkkinen, L. (2014). The benefits of extracurricular activities for socioemotional behavior and school achievement in middle childhood: An overview of the research. Journal of Educational Research Online, 6(3), 10-33.

Parcewska, T. (2020). Difficult situations and ways of coping with them in the experiences of parents homeschooling their children during the COVID-19 pandemic in Poland. Education 3-13. Advance online publication. https://doi.org/10.1080/03004279.2020.1812689.

Patrick, S. W., Henkhaus, L. E., Zickafoose, J. S., Lovell, K., Halvorson, A., Loch, S., Letterie, M., \& Davis, M. M. (2020). Wellbeing of parents and children during the pandemic: A national survey. Pediatrics, 146(4). https://doi.org/10.1542/peds. 2020-016824.

Pew Research Center (2015, December 17). Children's extracurricular activities. https://www.pewresearch.org/social-trends/2015/12/17/ 5-childrens-extracurricular-activities/.

Pew Research Center (2020, October 29). Most parents of K-12 students learning online worry about them falling behind. https://www.pewresearch.org/social-trends/wp-content/uploads/ sites/3/2020/10/PSDT_10.29.20_kids.edu_.full_.pdf.

Pramling Samuelsson, I., Wagner, J. T., \& Eriksen Ødegaard, E. (2020). The coronavirus pandemic and lessons learned in preschools in Norway, Sweden and the United States: OMEP policy forum. International Journal of Early Childhood, 52(2), 129-144. https://doi.org/10.1007/s13158-020-00267-3.

Prime, H., Wade, M., \& Browne, D. T. (2020). Risk and resilience in family well-being during the COVID-19 pandemic. American Psychologist, 75(5), 631-643. https://doi.org/10.1037/a mp0000660.
Ramos, G. \& Scarpetta, S. (2020). Combatting COVID-19's effect on children. OECD Policy Responses to Coronavirus (COVID-19). http://www.oecd.org/coronavirus/policy-responses/combattingcovid-19-s-effect-on-children-2e1f3b2f/\#contactinfo-d7e8271.

Reilly, K. (2020, August 31). Public schools will struggle even more as parents move kids to private ones during the pandemic. Time Magazine. https://time.com/5885106/school-reopening-corona virus/.

Salari, N., Hosseinian-Far, A., Jalali, R., Rostam, J., Vaisi-Raygani, A., Rasoulpoor, S., Mohammadi, M., Rasoulpoor, S., \& KhalediPaveh, B. (2020). Prevalence of stress, anxiety, depression among the general population during the COVID-19 pandemic: A systematic review and meta-analysis. Global Health, 16, 57 https:// doi.org/10.1186/s12992-020-00589-w.

Shafer, K., Milkie, M., \& Scheibling, C. (2020). The division of domestic labor before and during the COVID-19 pandemic in Canada: Stagnation versus shifts in father's contributions. Canadian Review of Sociology, 57(4), 523-549. https://doi.org/ 10.31235/osf.io/24j87.

Spinelli, M., Lionetti, F., Pastore, M., \& Fasolo, M. (2020). Parents' stress and children's psychological problems in families facing the COVID-19 outbreak in Italy. Frontiers in Psychology, 11. https://doi.org/10.3389/fpsyg.2020.01713.

Twenge, J. M., \& Joiner, T. E. (2020). Mental distress among U.S. adults during the COVID-19 pandemic. Journal of Clinical Psychology, 76(2), 2170-2182. https://doi.org/10.1002/jclp. 23064.

Walsh, F. (2015). Strengthening family resilience. Guilford Press.

Wang, K. Y. (2020). Information behavior of parents during COVID19 in relation to their young school-age children's education. The Serials Librarian, 79(1-2). https://doi.org/10.1080/0361526X. 2020.1806179.

Waters, L., \& Sunm, J. (2016). Can a brief strength-based parenting intervention boost self-efficacy and positive emotions in parents? International Journal of Applied Positive Psychology, 1, 41-56. https://doi.org/10.1007/s41042-017-0007-x.

Wittkowski, A., Garrett, C., Calam, R., \& Weisberg, D. (2017). Selfreport measures of parental self-efficacy: A systematic review of the current literature. Journal of Child and Family Studies, 26, 2960-2978. https://doi.org/10.1007/s10826-017-0830-5.

Yoshikawa, H., Wuermli, A. J., Britto, P. R., Dreyer, B., Leckman, J. F., Lye, S., Ponguta, L. A., Richter, L. M., \& Stein, A. (2020). Effects of the global COVID-19 pandemic on early childhood development: Short and long-term risks and mitigating program and policy actions. Journal of Pediatrics, 223, 188-193. https:// doi.org/10.1016/j.jpeds.2020.05.020. 